\title{
N89-29925
}

\section{P.7 SPECTRAL ANALYSIS OF TEMPERATURE AND BRUNT-VÄISÄLÄ FREQUENCY FLUCTUATIONS OBSERVED BY RADIOSONDES}

\author{
T. Tsuda, T. E. VanZandt \\ NOAA Aeronomy Laboratory, R/E/AL3 \\ 325 Broadway, Boulder, CO 80303 \\ S. Kato, S. Fukao, and T. Sato \\ Radio Atmospheric Science Center \\ Kyoto University, Uji, Kyoto 611 Japan
}

Recent studies have revealed that vertical wave number spectra of wind velocity and temperature fluctuations in the troposphere and the lower stratosphere are fairly well explained by a saturated gravity wave spectrum. But $\mathrm{N}^{2}$ (N: Brunt-Väisälä (BV) frequency) spectra seem to be better for testing the scaling of the vertical wave number spectra in layers with different stratifications, because its energy density is proportional only to the background value of $\mathrm{N}^{2}$, while that for temperature depends on both the BV frequency and the potential temperature. From temperature profiles observed in June-August 1987 over the MU Observatory, Japan, by using a radiosonde with $30 \mathrm{~m}$ height resolution, $\mathrm{N}^{2}$ spectra are determined in the $2-8.5 \mathrm{~km}$ (troposphere) and $18.5-25 \mathrm{~km}$ (lower stratosphere) ranges. Although individual spectra show fairly large day-by-day variability, the slope of the median of 34 spectra agrees reasonably with the theoretical value of -1 in the wave number range of $6 x$ $10^{-4} \sim 3 \times 10^{-3}(\mathrm{c} / \mathrm{m})$. The ratio of the spectral energy between these two height regions is about equal to the ratio of $\mathrm{N}^{2}$, consistent with the prediction of saturated gravity wave theory.

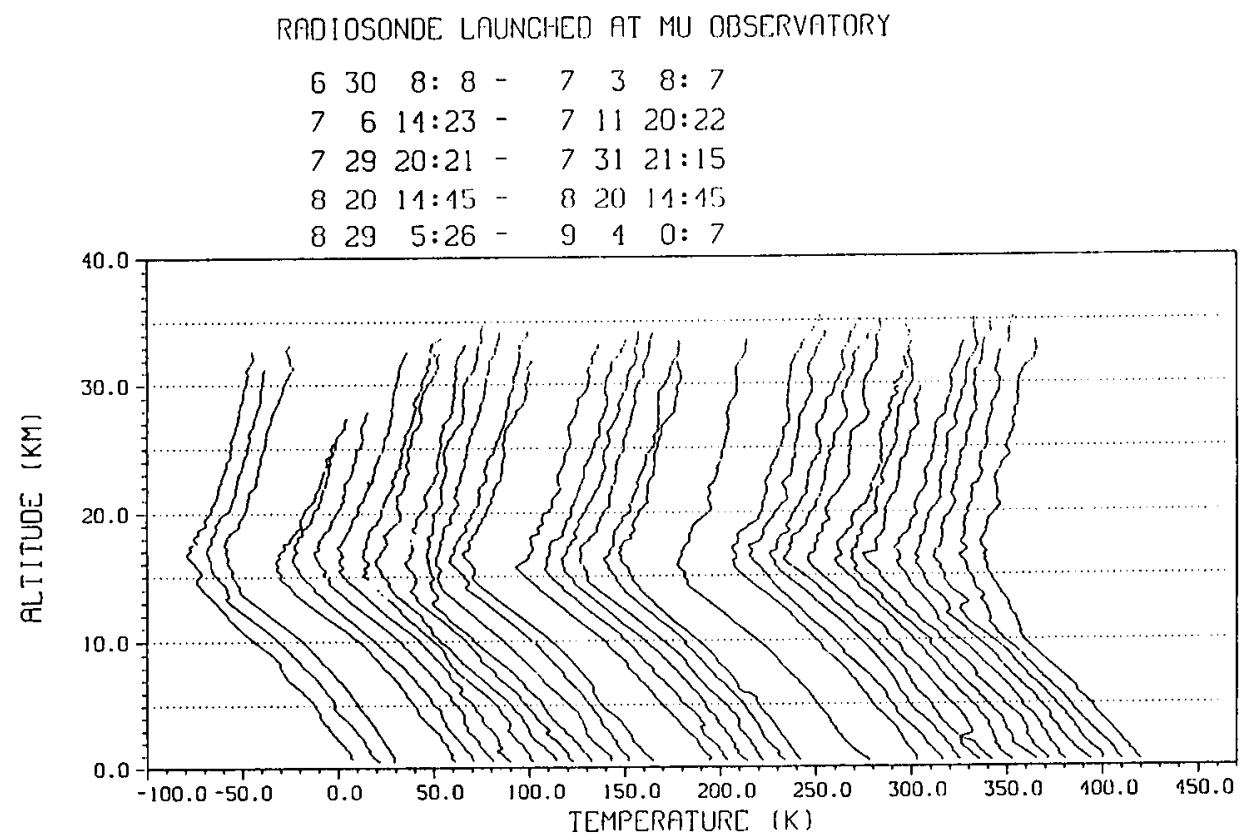

Figure 1. Temperature profiles observed by radiosondes launched from the MU radar site from 30 June to 4 September 1987 . The campaign periods are listed above. Successive profiles are displaced by $10 \mathrm{~K}$, and the beginning of each campaign is displaced by $20 \mathrm{~K}$. 

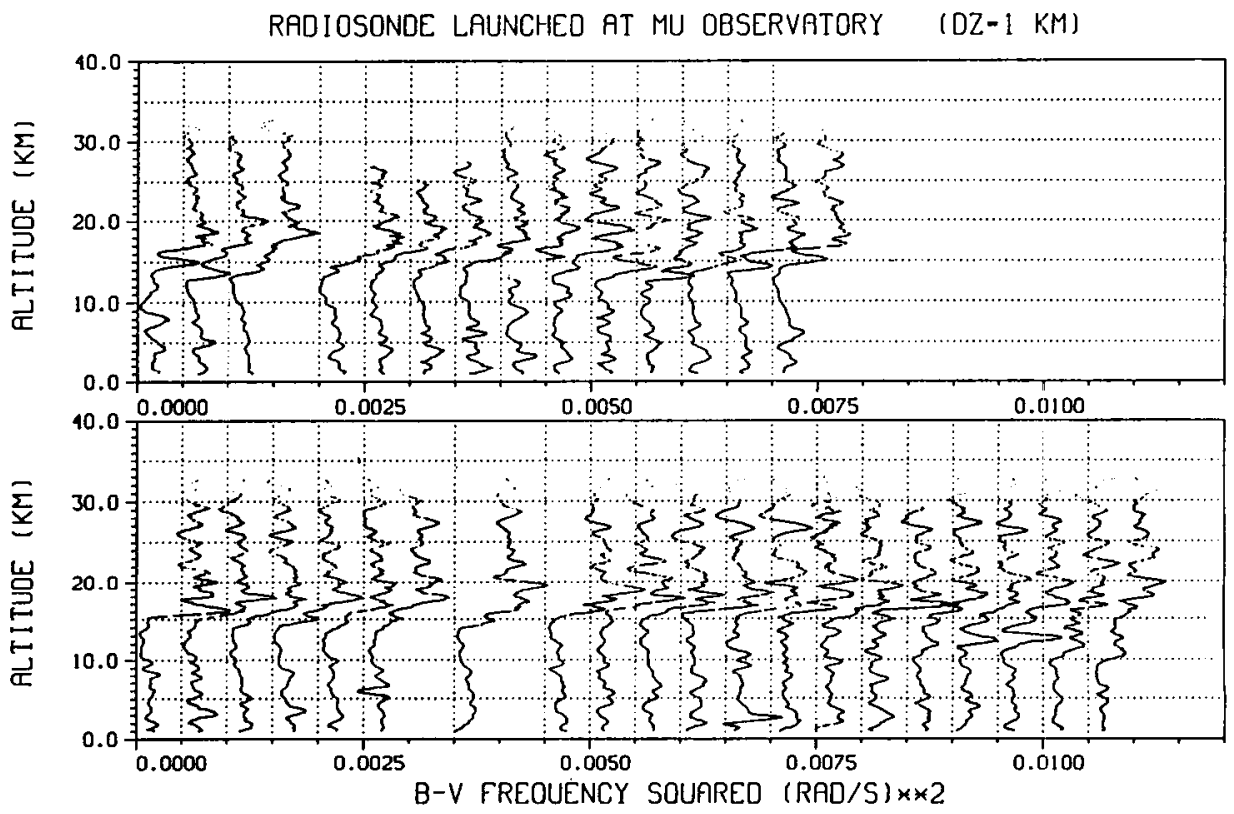

Figure 2. $\mathrm{N}^{2}$ profiles determined from the temperature profiles plotted in Figure 1 . The spacing for a calculation of the vertical derivative is $990 \mathrm{~m}$. Successive profiles are displaced by $5 \times 10^{-4}(\mathrm{rad} / \mathrm{s})^{2}$.

RADIOSONDE LAUNCHED AT MU OBSERVATORY

$$
\begin{aligned}
& 122214: 28-1226 \quad 4: 56 \\
& 2178: 43-21820: 25 \\
& 22315: 1-22519: 55
\end{aligned}
$$

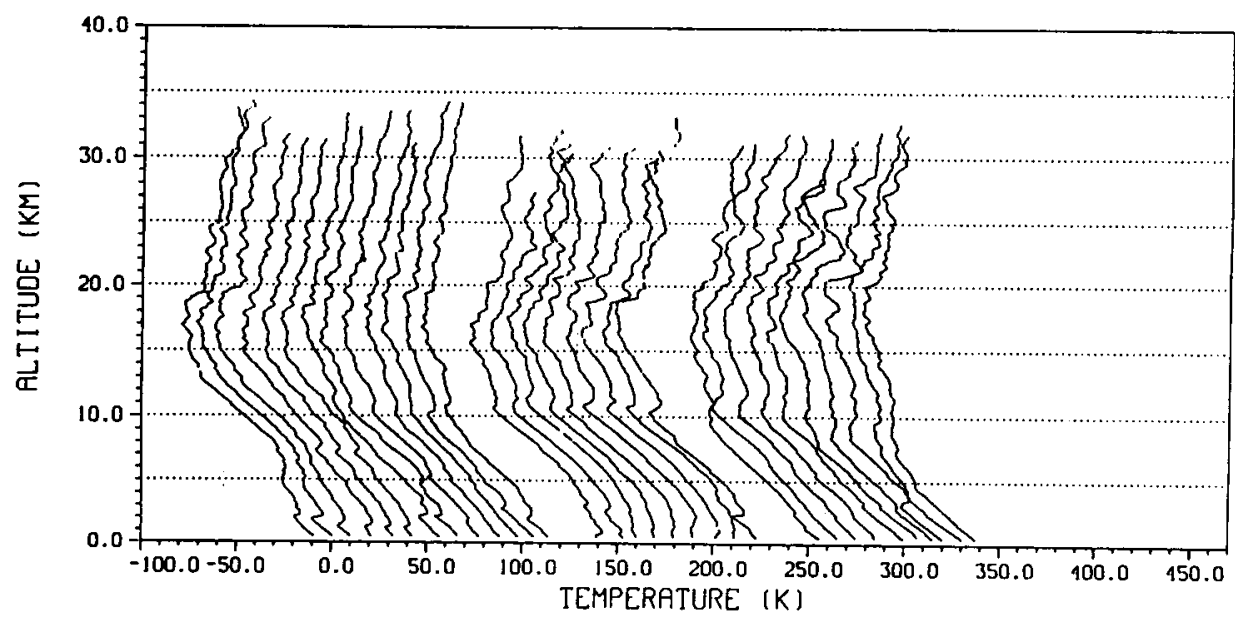

Figure 3. The same as Figure 1 except for the winter campaigns from 22 December 1986 to 25 February 1987. 


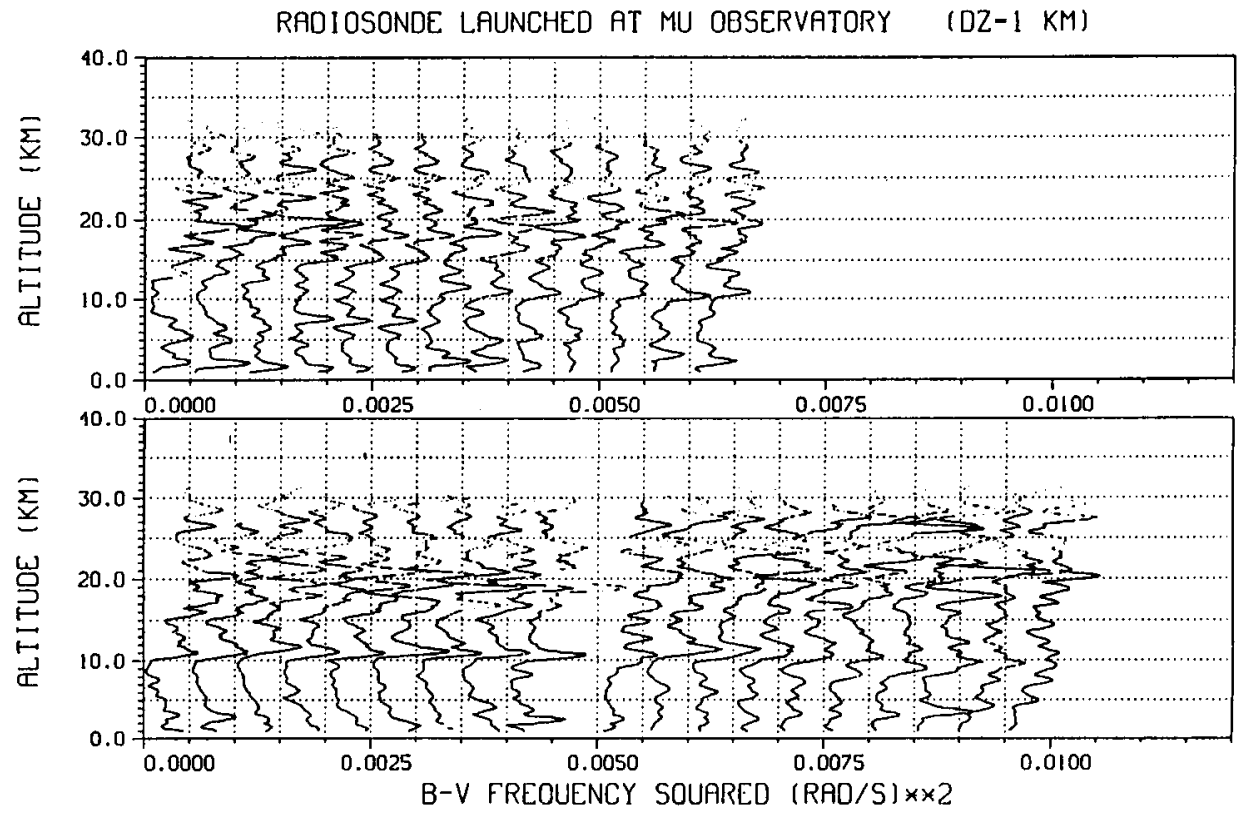

Figure 4. The same as Figure 2 except for the winter campaigns.

SPECTRAL FNALYSIS OF NORMALIZED IEMPERATURE

MEAN VALUE
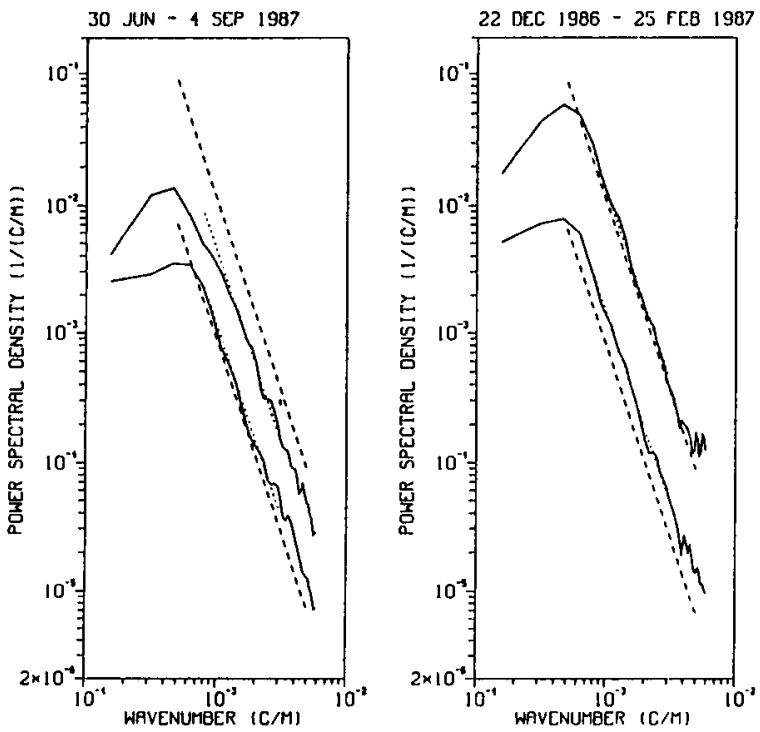

Figure 5. Mean vertical wave number spectra of normalized temperature perturbations in summer (left panel) and winter (right panel). The spectra with larger amplitudes are from $18.5-24.5 \mathrm{~km}$ altitude, while the others are from 2.0 $8.5 \mathrm{~km}$. The dashed curves correspond to a saturated gravity wave spectrum [Smith et al., 1987]. The dotted lines are the bestfits determined from the mean value of $\mathrm{F}(\mathrm{m}) \mathrm{m}^{3}$ averaged for $\mathrm{m}=8 \times 10^{4}$ to $3 \times 10^{3}$, where $F(\mathrm{~m})$ and $\mathrm{m}$ are power spectral density and wave number, respectively. 
SPECTRAL ANALYSIS OF ARUNT-VAISALA FREOUENCY SOUAREO MLFN VALUE
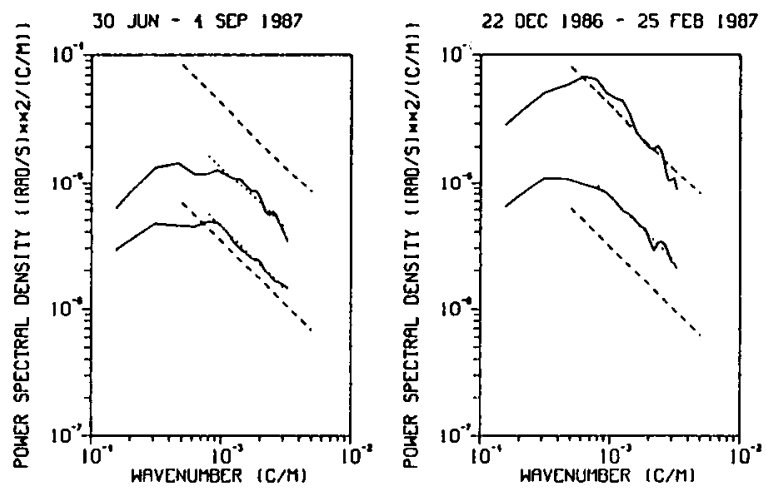

$18.47-24.95 \mathrm{KM}$ Nw×2- .649E-03

16.47-24.95 KM N*x2- .636E-03

EMM- .135E-07

ExM- .111E-07

1.97- $0.45 \mathrm{KM}$ NW\%2- $.181 \mathrm{E}-03$

1.97- 8.15 KM NWM2- .175E-03

EXM- .750E-00

Figure 6. Same as Figure 5 except for $\mathrm{N}^{2}$ spectra. The vertical spacing to calculate $\mathrm{N}^{2}$ is 150 $\mathrm{m}$. The median value of background $\mathrm{N}^{2}$ in each height range is shown at the bottom of the pane, which is used to calculate the theoretical predictions plotted in Figures 5 and 6. 


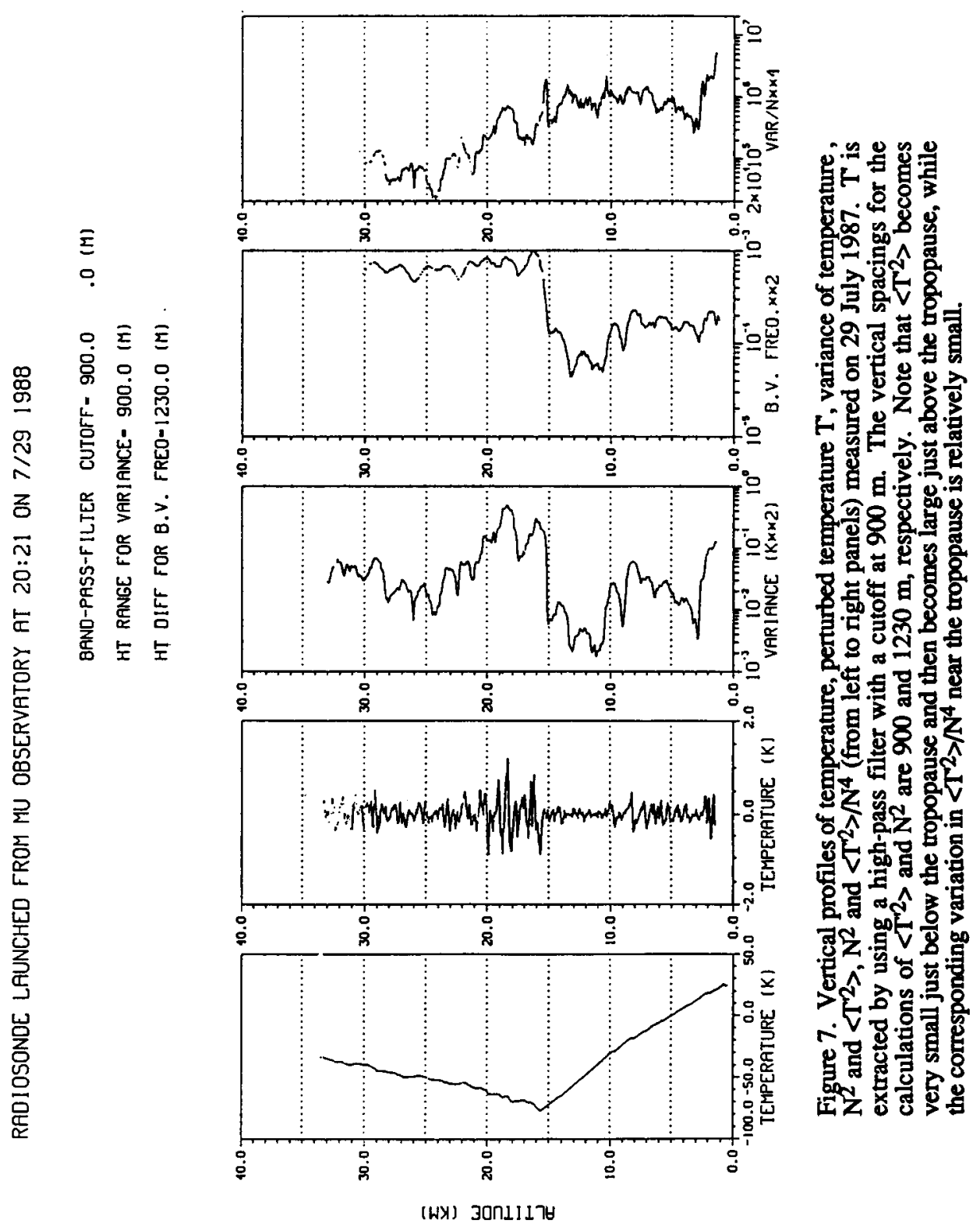




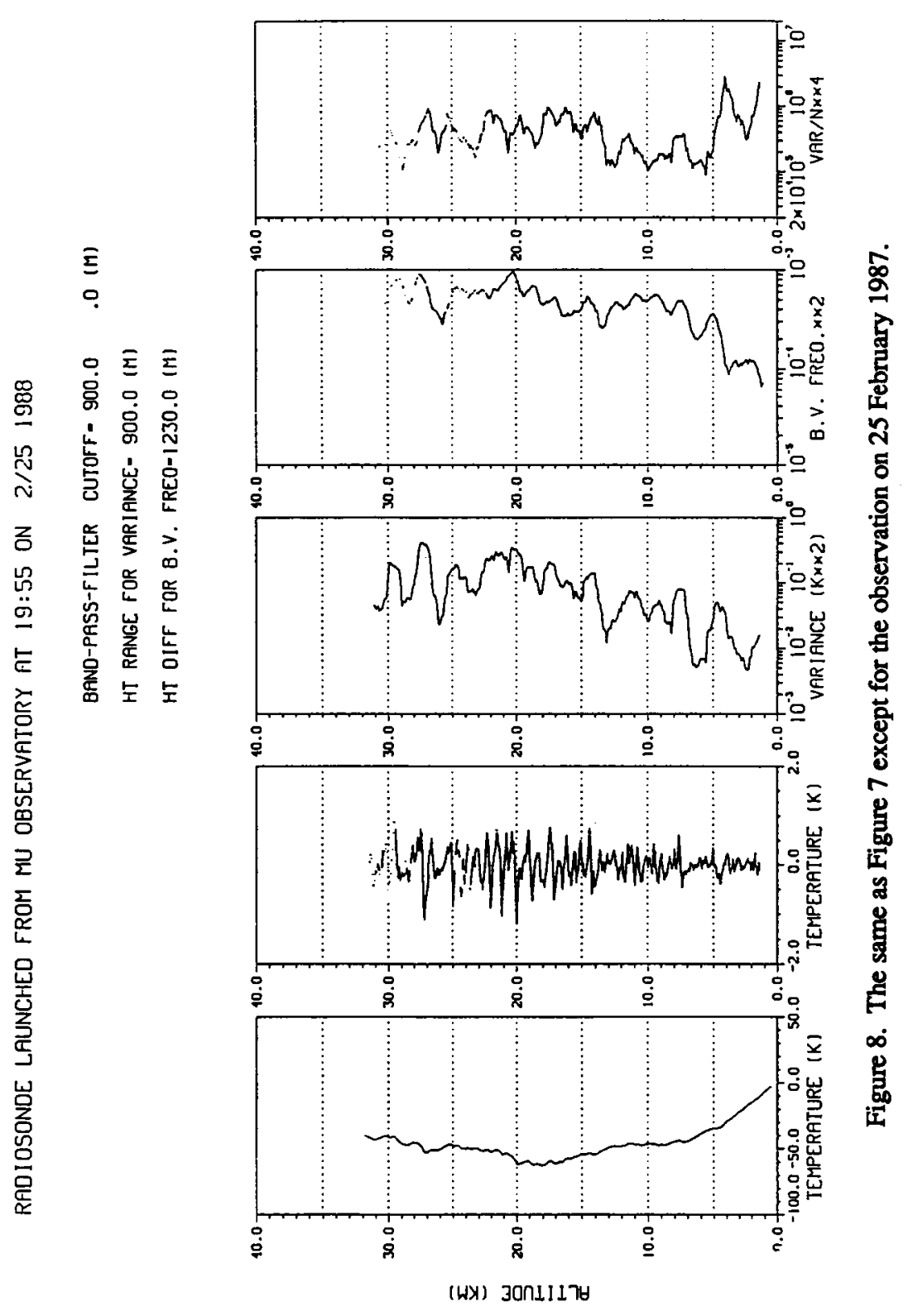


RADIOSONDE LAUNCHED AT MU OBSERVATORY

BAND-PASS-FILTER CUTOFF- $900.0 \quad .0(\mathrm{M})$

HT RANGE FOR VARIANCE- 900.0 (M)

HT DIFF FOR B.V. FREO-1230.0 (M)
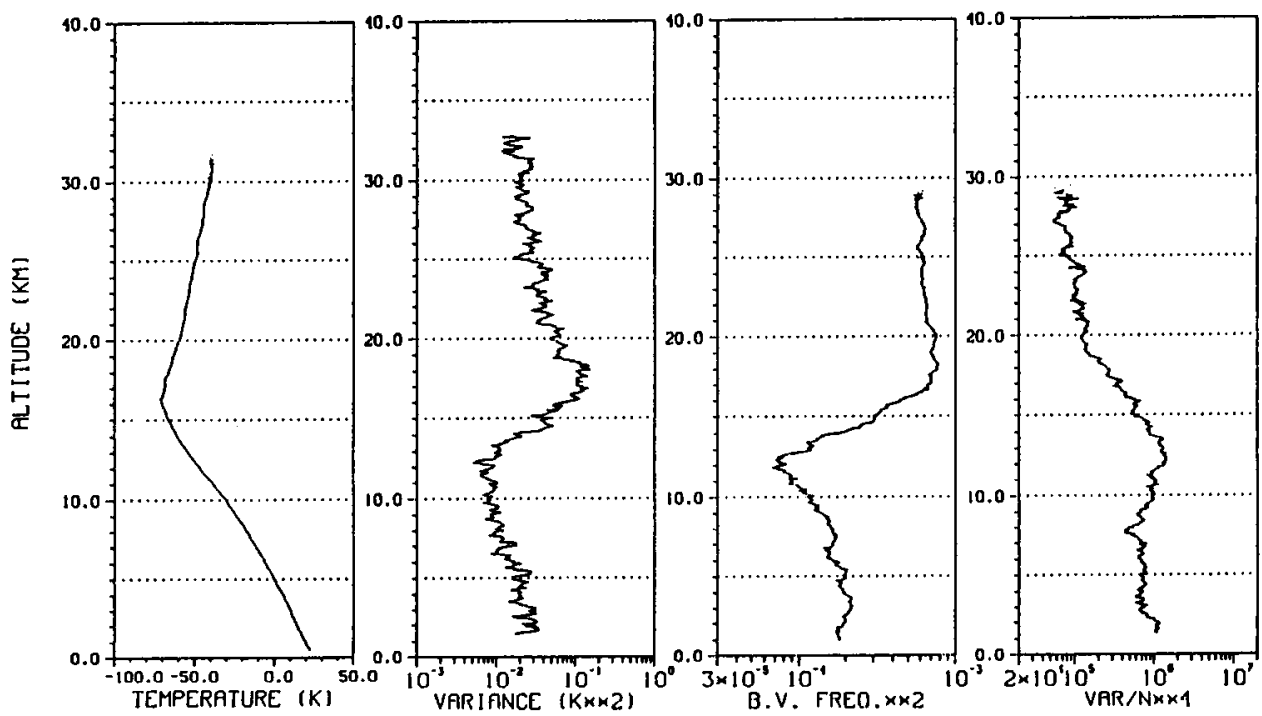

Figure 9. Profiles of temperature $\left\langle\mathrm{T}^{2}\right\rangle, \mathrm{N}^{2}$, and $\left\langle\mathrm{T}^{2}\right\rangle / \mathrm{N}^{4}$ determined as the median of 34 observations in summer months. Note that $\left\langle\mathrm{T}^{2}\right\rangle / \mathrm{N}^{4}$ is fairly constant in the troposphere and stratosphere, although their amplitudes differ by a factor of about 8 . 
RADIOSONDE LAUNCHED AT MU OBSERVATORY

BAND-PASS-FILTER CUTOFF- $900.0 \quad .0$ (M)

HT RANGE FOR VARIANCE- 900.0 (M)

HT OIFF FOR B.V. FREO-1230.0 (M)
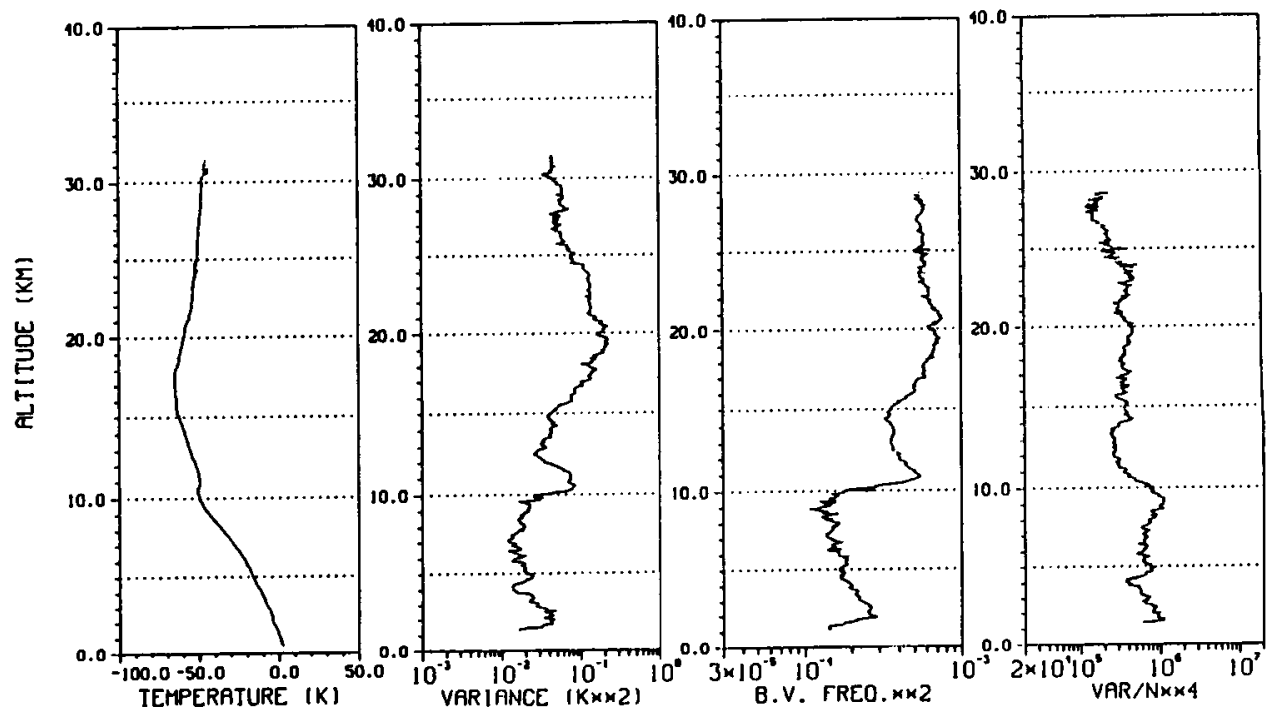

Figure 10. The same as Figure 9 except for 32 winter observations. The difference in $\left\langle\mathrm{T}^{2}>/ \mathrm{N}^{4}\right.$ between the troposphere and stratosphere is smaller than in the summer case. 